\title{
Bearing the brunt of covid-19: older people in low and middle income countries
}

\author{
A global expert group on older people might be useful
}

\author{
Peter Lloyd-Sherlock professor ${ }^{1}$, Shah Ebrahim honorary professor ${ }^{2}$, Leon Geffen director ${ }^{3}$, Martin \\ McKee professor of European public health ${ }^{2}$
}

${ }^{1}$ School of International Development, University of East Anglia, Norwich, UK; ' 2 London School of Hygiene and Tropical Medicine, London, UK; ${ }^{3}$ Samson Institute For Ageing Research (SIFAR), Cape Town, South Africa

\begin{abstract}
The global response to covid-19 has been described as being "too little, too late." ${ }^{1}$ National and international efforts are now gathering pace. Those involved in these efforts can draw on a rapidly growing body of research, much summarised in regularly updated guidelines published by national and international authorities, covering the latest information on the virus, its mode of transmission, its spread, and the susceptibility of different groups within the population.

Although many aspects of this new infection remain uncertain, one thing is already clear. The risk of dying from covid-19 increases with age, and most of the deaths observed are in people older than 60 , especially those with chronic conditions such as cardiovascular disease. This has important implications for the way in which public health and clinical responses should be developed. Yet, to date, guidance largely ignores this issue, not only in high income countries, ${ }^{2}$ but in low and middle income countries (LMICs), which contain 69\% of the global population aged $\geq 60$ and where health systems are weaker and covid-19 could potentially have the greatest impact.
\end{abstract}

\section{Four concerns}

In LMIC settings, there are at least four issues to consider. The first is the changing family dynamics. Increasing opportunities for labour mobility mean that in many countries, one, or sometimes both, parents live and work distantly, with their children brought up by grandparents. Improvements in healthcare have allowed many of these older carers to survive with chronic disorders that, in earlier times, would have killed them. Should they become ill with covid-19 or, worse, die, the implications for their extended families will be profound, beyond grief and bereavement, especially when those working abroad are unable to return at short notice. Moreover, these caregiving roles provide an added risk of exposure for older people as it makes it impossible for them to self-quarantine.

A second concern is that increasing numbers of very old people are now being cared for in nursing homes or similar facilities in LMICs. ${ }^{3}$ These homes are often unregulated and provide care that is of very poor quality. Institutions in which people live in close proximity, such as prisons and mines, can act as incubators of infection. ${ }^{4}$ Already, there is evidence implicating nursing homes in the spread of this virus in high income countries, ${ }^{5}$ and it would not be surprising if the threat was even greater in lower income countries. Residents in such facilities are highly dependent on their staff, and a severe outbreak, which some estimates suggest could afflict up to $60 \%$ of the population, ${ }^{6}$ would have serious implications for the welfare and, potentially, survival of their residents. In fact, the risk of infection may be similarly high for older people living at home in LIMCs, where conditions are often cramped and overcrowded.

A third problem is the ability of health systems to cope with surges in demand, especially for those needing respiratory support, a disproportionate number of whom are likely to be older. Health systems in LMICs face severe constraints on capacity at normal times and are unlikely to be able to offer the care needed, especially if the precarious staffing levels- already depleted by migration, low salaries, and poor working conditions ${ }^{7}$ - and limited gerontological expertise are reduced further by illness.

In many LMICs, older people already face great barriers of access to health services and support, including affordability and age based discrimination. ${ }^{8}$ The global spread of covid-19, and its disproportionate effect on older people, risks increasing inequity in health systems and the further marginalisation of older people. The capacity of health systems in these countries to screen, let alone treat, covid-19, will be very limited. In South Africa each test costs around $\$ 75(£ 60 ; € 67)$ - this exceeds total government per head health spending in many LMICs, such as Bangladesh (\$34), Benin (\$30), or Haiti (\$38). ${ }^{9}$ N95 masks are in short supply and cost around $\$ 9$ each in South Africa.

A fourth issue relates to the inclusion of older people in developing responses. Social distancing policies must consider 
the already precarious existence of many older people, particularly those living alone or dependent on others for care and support. These older people may face barriers to obtaining food and other essential supplies if quarantine conditions become more widespread. Policy makers should bear in mind that a large number of older people in LMICs are illiterate.

\section{Acknowledging the problem}

It will not be easy to deal with these problems, especially in settings where there is often weak public health infrastructure, a lack of gerontological expertise at all levels of the health system, and limited trust in government. However, a first step would be to recognise that these problems exist. An age perspective should be included explicitly in the development of national and global planning for covid-19, and a global expert group on older people should be formed to support with guidance and response to the virus in both residential facilities and home settings. As new knowledge emerges, this group can identify and evaluate cost effective therapies and interventions that respond to the particular needs of older people in LMICs living in challenging settings, where formal health service infrastructure is limited.

Previously, some of the authors have argued that global health priority setting is institutionally ageist. ${ }^{10}$ Covid- 19 offers an opportunity to prove us wrong.

We thank Rachel Albone, John Beard, Alex Kalache, Des O'Neill, Siriphan Sasat, and Lucas Sempe for their contribution to this editorial. Support also came from Justin Derbyshire (HelpAge International), Jane Barratt (International Federation of Ageing), Srinath Reddy (Public Health Foundation of India), Jacqueline Angel
(Treasurer International Association of Geriatrics and Gerontology), Carlos André Uehara (Brazilian Society of Geriatrics and Gerontology), Piu Chan (National Clinical Research Center for Geriatric Disorders, China), and Enrique Vegas (Pan American Health Organization).

Competing interests: We have read and understood BMJ policy on declaration of interests and have no relevant interests to declare.

Provenance and peer review: Not commissioned; not externally peer reviewed.

1 The Lancet. COVID-19: too little, too late? Lancet 2020;395:755. 10.1016/S0140-6736(20)30522-5 32145772

2 Dooley B, Rich M, Inoue M. In graying Japan, many are vulnerable but few are being tested. New York Times 2020 Mar 2. https://www.nytimes.com/2020/02/29/world/asia/ japan-elderly-coronavirus.html

3 Adamek M, Balaswamy S. Long term care for elders in developing countries in Asia and Africa: a systematic review. Gerontologist 2016;56:413-1310.1093/geront/gnw162.1650

4 Basu S, Stuckler D, McKee M. Addressing institutional amplifiers in the dynamics and control of tuberculosis epidemics. Am J Trop Med Hyg 2011;84:30-7. 10.4269/aitmh.2011.10-0472 21212197

5 Boodman E, Branswell H. First Covid-19 outbreak in a US nursing home raises concerns. 2020. Feb 29. https://www.statnews.com/2020/02/29/new-covid-19-death-raises-concernsabout-virus-spread-in-nursing-homes/

6 Anderson RM, Heesterbeek H, Klinkenberg D, etal . How will country-based mitigation measures influence the course of the COVID-19 epidemic? Lancet 2020. [Epub ahead of print.] 10.1016/S0140-6736(20)30567-5

7 World Health Organization. A universal truth: no health without a workforce. WHO, 2013. Sleap B. The freedom to decide: what older people say about their rights to autonomy and independence. 2018. https://www.helpage.org/blogs/bridget-sleap-24/the-freedomto-decide-what-older-people-say-about-their-rights-to-autonomy-and-independence-1059/

9 World Bank. World development indicators 2020. Current health expenditure per capita (current US\$). https://data.worldbank.org/indicator/SH.XPD.CHEX.PC.CD

10 Lloyd-Sherlock PG, Ebrahim S, McKee M, Prince MJ. Institutional ageism in global health policy. BMJ 2016;354:i4514. 10.1136/bmj.i4514 27582131

Published by the BMJ Publishing Group Limited. For permission to use (where not already granted under a licence) please go to http://group.bmj.com/group/rights-licensing/ permissions 